\title{
The influence of soil structure and air content on gas diffusion in soils
}

\author{
J. W. Bakker and A. P. Hidding
}

Institute for Land and Water Management Research, Wageningen, the Netherlands

Received 3 July 1969

\section{Summary}

A method to determine the diffusion coefficient of oxygen in undisturbed soil samples is described. Calculations are made of the errors involved when neglecting the storage term, the temperature and pressure variations, the oxygen consumption and the resistance of the ambient air.

The diffusion coefficient $\left(D_{\mathrm{s}}\right)$ is a function of air porosity $\left(\varepsilon_{\mathrm{g}}\right)$ and of soil structure. It appears that at values of $\varepsilon_{\mathrm{g}}$ below 0.20 , the effect of a puddled soil surface becomes evident. In puddled soils $D_{s}$ is at equal $\varepsilon_{\mathrm{g}}$ far below the $D_{8}$ in non-puddled soils. These differences increase with decreasing $\varepsilon_{\mathrm{g}}$.

Calculated are, for a tulip crop in spring time, the gradients of oxygen concentration in the soil atmosphere needed for the supply of oxygen to the plant roots. The calculation shows that a wet soil crust can limit the gas exchange by diffusion to a very great extent.

\section{Introduction}

Mechanical harvesting of root and bulb crops grown on heavy clay soils is often extremely difficult. For this reason the use of lighter soils for these crops is preferable. Heavy clay soils, however, may be improved for mechanical harvesting by lowering the clay content of the topsoil by means of ploughing up lighter soils or by mixing the topsoil with sand. A disadvantage of some lighter soils, however, is their unstable structure, which can easily be destroyed by rain or long lasting wet circumstances. In such a case soil particles often are washed down and fill up greater pores. This 'puddling' causes a high-density layer at the surface. These puddled surface soils have a very low permeability for water and for air, which may cause insufficient aeration and severe damage to crops.

In the Netherlands, up till now the structure of a topsoil in regard to aeration has been characterized by the air porosity measured at field capacity ( $\mathrm{pF} 2.0$ ) or during a wet period (Boekel, 1963; Boekel and Pelgrum, 1966). The relation between plant growth and air porosity is, however, different for different soils.

An improvement in the evaluation of the structure with regard to aeration could be the determination of the diffusion coefficient of gases in a soil, because the diffusion coefficient mainly determines the gas transport in the soil (Buckingham, 1904; Romell, 1922). The diffusion coefficient for gas in water is about $10^{-4}$ times that in air. It is evident that the main gas diffusion takes place through the air-filled pores of the soil 
only. Besides volume, shape and especially continuity of the air-filled pores is important for gas diffusion. One may expect that in puddled soils more blocked pores are present than in soils with a good structure.

The influence of structure and air porosity on gas diffusion in surface soils was investigated, with special attention to wet puddled soils.

\section{Review of literature}

The gas diffusion in the soil is commonly given as a ratio $D_{s} / D_{a}, D_{s}$ being the coefficient of diffusion in the soil (in $\mathrm{cm}^{2}, \mathrm{sec}^{-1}$ ) and $\mathrm{D}_{\mathrm{a}}$ being the coefficient of diffusion of the same gas in air at the same temperature and pressure. The ratio $D_{s} / D_{a}$ depends on the soil only and not on the gas used for diffusion measurement (Penman, 1940).

The relationship between $D_{s} / D_{a}$ and air porosity $\varepsilon_{\mathrm{g}}\left(\mathrm{cm}^{3}\right.$ air. $\mathrm{cm}^{-3}$ soil) can be described over a wide range of air porosity values by an equation of the form

$\mathrm{D}_{\mathrm{s}} / \mathrm{D}_{\mathrm{a}}=\gamma \varepsilon_{\mathrm{g}}^{\mu}$ (Currie, 1960)

For a short range of $\varepsilon_{\mathrm{g}}$ values, however, the relationship can be described by a linear equation of the form

$\mathrm{D}_{\mathrm{s}} / \mathrm{D}_{\mathrm{a}}=\mathrm{a}\left(\varepsilon_{\mathrm{B}}-\mathrm{b}\right)$

In Table 1 several published data of these relationships are given.

It is remarkable that only few measurements of diffusion at low air porosities are available, the range that is of special importance. The factor $b$, which is interpreted as the volume of blocked pores (van Duin, 1956; Call, 1957) is higher in wet soils than in dry soils at the same ranges of $\varepsilon_{\mathrm{g}}$. It should, however, be kept in mind that the factor $b$ cannot be an exact indication of the amount of blocked pores only, because in a wet soil it increases with an increase in $\varepsilon_{\mathrm{g}}$ (Penman, 1940; Currie, 1960, 1961; Gradwell, 1961, 1965; see Table 1), which is not in accordance with the mentioned interpretation of $b$.

In disturbed soil samples (Table $1 \mathrm{a}$ and $\mathrm{b}$ ) differences in diffusion between the different soils are small. The reason may be that sieving and artificially packing the samples results in a disappearance of the existing differences in structure of the original soils.

Investigations between samples with different structure (Table 1c) show a significant influence of structure on the relation between $\varepsilon_{\mathrm{a}}$ and $\mathrm{D}_{\mathrm{s}} / \mathrm{D}_{\mathrm{a}}$, especially at lower values of $\varepsilon_{\mathrm{g}}$.

\section{Determination gas diffusion coefficient}

\section{Principle}

The determination of the gas diffusion coefficient of a soil sample is based on the measurement of the amount of gases which diffuse per unit time and per unit concentration difference.

The diffusion in one direction can be described as: 
Table 1 Relation between air porosity $\varepsilon_{\mathrm{g}}$ and gas diffusion in soils $D_{\mathrm{s}} / D_{\mathrm{a}}$

Author Year $\quad$ Material $\quad \varepsilon_{\mathrm{g}} \quad D_{\mathrm{s}} D_{\mathrm{a}}$

a. Disturbed dry material

\begin{tabular}{|c|c|c|c|c|c|}
\hline Penman & 1940 & sand, soil and glass spheres & $\begin{array}{r}0.18-0.50 \\
>0.50\end{array}$ & $\begin{array}{l}0.66 \\
1.0\end{array}$ & $\frac{\varepsilon_{g}}{\left(\varepsilon_{g}-0.25\right)}$ \\
\hline Currie & 1960 & sand, glass spheres, carborundum & $0.20-0.55$ & $\begin{array}{l}0.7 \\
0.9\end{array}$ & $\begin{array}{l}\left(\varepsilon_{\mathrm{g}}-0.05 \text { à } 0.1\right) \\
\varepsilon_{\mathrm{g}}{ }^{1.4}\end{array}$ \\
\hline van Bavel & 1952 & $\begin{array}{l}\text { sand } \\
\text { mixtures of sand and soil } \\
\text { mixtures of sand, soil and glass } \\
\text { spheres }\end{array}$ & $\begin{array}{l}0.415 \\
0.315 \\
0.250\end{array}$ & 0.6 & B \\
\hline
\end{tabular}

b. Disturbed wet material

\begin{tabular}{|c|c|c|c|c|}
\hline Taylor & 1949 & $\begin{array}{c}\text { sand (porosity } 0.39-0.45 \text { ) } \\
\text { ibid }\end{array}$ & $0.04-0.15$ & $0.55 \varepsilon_{\mathrm{g}}$ \\
\hline Currie & 1961 & sand (porosity 0.38 ) & $\begin{array}{l}0.13-0.43 \\
0.05-0.18\end{array}$ & $1.0\left(\varepsilon_{\mathbf{g}}-0.09\right)$ \\
\hline & & ibid & $0.18-0.30$ & $0.8 \quad\left(\varepsilon_{g}-0.15\right)$ \\
\hline & & ibid & $>0.16$ & $6.0 \varepsilon_{g^{3.4}}$ \\
\hline Taylor & 1949 & loam & $0.1-0.49$ & $0.67 \varepsilon_{g}$ \\
\hline Penman & 1940 & 'Rothamsted subsoil' & $0.15-0.5$ & $0.66 \varepsilon g$ \\
\hline Call & 1957 & several soils & $0.14-0.39$ & $0.66\left(\varepsilon_{\mathcal{g}}-0.1\right)$ \\
\hline Gradwell & 1965 & clay loam & $0.02-0.09$ & $0.06\left(\varepsilon_{\mathrm{g}}-0.02\right)$ \\
\hline Grable and Siemer & 1968 & $\begin{array}{l}\text { jbid } \\
\text { silty clay loam }(6.8 \% \text { organic } \\
\text { matter })\end{array}$ & $\begin{array}{l}0.09-0.16 \\
0.2-0.4\end{array}$ & $\begin{array}{ll}0.3 & \left(\varepsilon_{\mathrm{g}}-0.07\right) \\
5.25 & \varepsilon_{\mathrm{g}}{ }^{3.36}\end{array}$ \\
\hline c. Soils with differen & tructur & & & \\
\hline Blake and Page & 1948 & $\begin{array}{l}\text { clay soils measured in situ } \\
\text { blocky structure }\end{array}$ & $0.05-0.3$ & \\
\hline & & soil with more fine aggregates & $0.15-0.3$ & $1.3 \stackrel{\varepsilon g}{\varepsilon g}-0.1)$ \\
\hline Gradwell & 1961 & Kaolien aggregates & $0.12-0.33$ & $0.65\left(\varepsilon_{g}-0.1\right)$ \\
\hline & & $\begin{array}{l}\text { ibid dense packing } \\
\text { undisturbed samples from pasture }\end{array}$ & $0.22-0.33$ & $0.7\left(\varepsilon_{g}-0.17\right)$ \\
\hline Domby and Kohnke & 1956 & $\begin{array}{l}\text { topsoil (silt loam) } \\
\text { silt loam }\end{array}$ & $0.02-0.4$ & $0.27 \varepsilon_{\mathrm{g}}$ \\
\hline & & $\begin{array}{l}1 \text { with a soil crust } \\
2 \text { uncrusted }\end{array}$ & 0.13 & $D_{s 1} / D_{s 2}=0.55$ \\
\hline & & $\begin{array}{l}1 \text { with a soil crust } \\
2 \text { incrusted }\end{array}$ & 0.25 & $D_{\mathrm{s} 1} / D_{\mathrm{s} 2}=1.0$ \\
\hline
\end{tabular}

$F \cdot A=\frac{d q}{d t}=-D_{s} \frac{d c}{d x} \cdot A$

$F=$ rate of transfer per unit area of section $\left(\mathrm{g} \cdot \mathrm{cm}^{-2} \cdot \mathrm{sec}^{-1}\right)$

$A=\operatorname{area}\left(\mathrm{cm}^{2}\right)$

$\mathrm{q}=$ amount of gas $(\mathrm{g})$

$\mathrm{t}=$ time (sec)

$\mathrm{c}=$ concentration $\left(\mathrm{g} \cdot \mathrm{cm}^{-3}\right)$

$\mathrm{x}=$ distance along the line of flow $(\mathrm{cm})$

Measurements can be made either at a constant concentration gradient, using for example saturated vapour of $\mathrm{CS}_{2}$, acetone or ethylene dibromide (Penman, 1940 and Call, 1957), or by a non-steady state technique. In the latter case the diffusion coefficient 
is calculated from the decrease in gas concentration with time in a cap placed over the soil sample, which at the other end is connected with the free atmosphere. Taylor (1949) and Currie (1960) applied such a technique using oxygen or hydrogen. In our experiments the non-steady state method with oxygen was used.

\section{Sampling and measuring}

Undisturbed samples of the top $5 \mathrm{~cm}$ soil layer were taken with a large stainless steel cylinder $6 \mathrm{~cm}$ high and $7.5 \mathrm{~cm}$ radius. A thin layer of the lower surface, which might have been smeared during sampling, was cut off with a small sharp knife. Small gaps between soil sample and the cylinder were filled with a plastic glue. The sample was placed on a supporting gauge wire $(0.7 \mathrm{~mm})$ box with openings of $2.0 \mathrm{~mm}$. A cap (height $10 \mathrm{~cm}$, area $124 \mathrm{~cm}^{2}$ ) was placed on the sample ring and an air-tight connection was made with plastic kit (see Fig. 1). The oxygen concentration in the cap was measured with a polarographic oxygen analyser (Beckman, Model 777) of which the membrane-covered electrode was placed in the cap. The oxygen concentration was registrated continuously with a recorder for a period of one to several hours after filling the cap with oxygen. Before and after each diffusion run the oxygen concentration of the ambient air under the sample was registrated. To prevent high evaporation losses, the humidity of the air was maintained at a high level during measurement.

Each first run was made with the sample having its in situ air porosity; later runs were made after successively drying the sample gradually to raise the air porosity.

\section{Calculation}

Neglecting storage of gases in the sample, Eq. 3 becomes

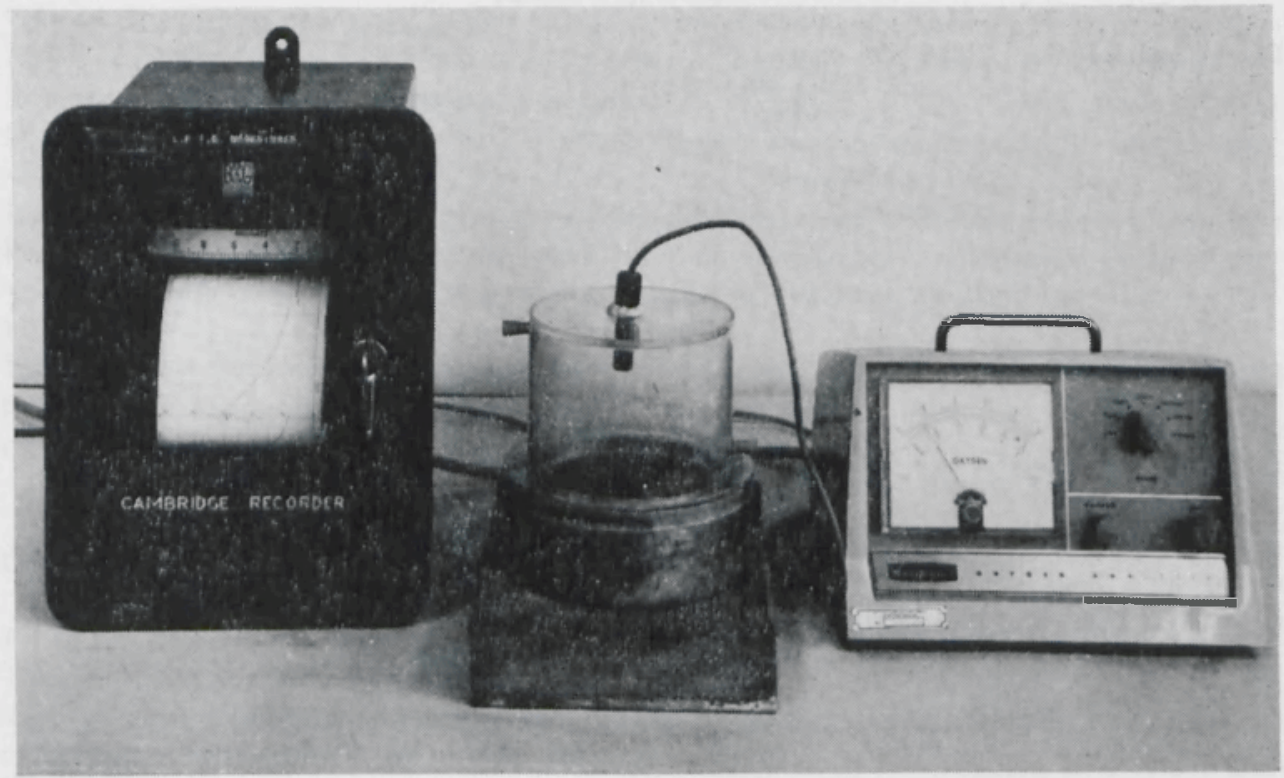

Fig. I Apparatus for the determination of oxygen diffusion through soil samples 
$\frac{\mathrm{dq}}{\mathrm{dt}}=-\mathrm{D}_{\mathrm{s}} \frac{\mathrm{C}_{\mathrm{c}}}{\mathrm{h}_{\mathrm{s}}} \cdot \mathrm{A}$

$\mathrm{C}_{\mathrm{c}}=$ concentration difference between both ends of the sample $\left(\mathrm{g} \cdot \mathrm{cm}^{-3}\right)$

$\mathrm{h}_{\mathbf{s}}=$ height of the sample $(\mathrm{cm})$

Concentration gradients of oxygen outside the soil sample are assumed to be negligible, compared with those inside the sample. The relation between concentration change in the cap and amount of gas diffusing through the sample can be given by

$\frac{d q}{d t}=-\frac{d C_{c}}{d t} h_{c} \cdot A$

where $h_{c} \cdot A=$ volume of the cap.

Combining Eq. 4 and 5 gives

$\frac{\mathrm{dC}_{\mathrm{c}}}{\mathrm{dt}} \cdot \mathrm{h}_{\mathrm{c}}=\frac{\mathrm{D}_{\mathrm{s}} \mathrm{C}_{\mathrm{c}}}{\mathrm{h}_{\mathrm{s}}}$

Solving Eq. 6 for the boundary conditions $t=0, C_{c}=C_{c o}$ and $t=t, C_{c}=C_{c t}$ gives:

$$
D_{s}=\frac{h_{s} \cdot h_{c}}{t} 2.303 \log \frac{C_{c o}}{C_{c t}}
$$

According to Eq. 7 there is a linear relationship between $t$ and $\log C_{e t}$ which is in accordance with the results of the diffusion measurements as represented in Fig. 2.

Taking into account the storage of oxygen in the sample, one has to substitute in Eq. 3, according to the law of continuity, the equation

$\frac{\mathrm{dF}}{\mathrm{dx}}=-\frac{1}{\varepsilon_{\mathrm{g}}} \frac{\mathrm{dc}}{\mathrm{dx}}$

which results in the general diffusion equation

$$
\frac{\mathrm{dc}}{\mathrm{dt}}=\frac{D_{\mathrm{s}} \mathrm{d}^{2} \mathrm{c}}{\varepsilon_{\mathrm{g}} \mathrm{dx}^{2}}
$$

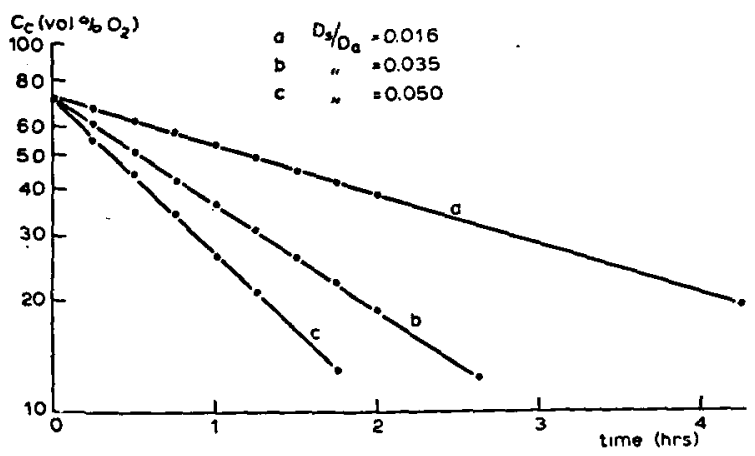

Neth. J. agric. Sci. 18 (1970)
Fig. 2 Oxygen concentration difference between both sample ends $\left(C_{\mathrm{c}}\right.$ expressed in vol. $\%)$ on logarithmic scale plotted against time, during some diffusion runs 
Solutions of this equation have been published for several problems of heat transfer. Mathematically the diffusion measurement here applied is analogous to the solution of Eq. 9 for heat transfer through a sheet of metal which is kept at a constant temperature at one side and at $t=0$ is brought in contact with a known amount of well stirred fluid of deviating temperature at the other side, as is given by Carslaw and Jaeger (1950, p. 128, Eq. 8) and Currie (1960):

$\frac{C_{c t}}{C_{c o}}=\sum_{n=1}^{n=\infty} \frac{2 \varepsilon_{g}}{h_{c}} \cdot \frac{e-D_{s} a_{n}^{2} \cdot t \cdot \varepsilon_{g}^{-1}}{h_{s}\left\{\alpha_{n}+\varepsilon_{g}^{2} h_{c}^{-2}\right\}+\varepsilon_{g} \cdot h_{c}-1}$

$a_{\mathrm{n}}=\mathrm{n}^{\text {th }}$ root of $\alpha \mathrm{h}_{\mathrm{s}} \tan \alpha \mathrm{h}_{\mathrm{s}}=\frac{\varepsilon_{\mathrm{g}} \mathrm{h}_{\mathrm{s}}}{\mathrm{h}_{\mathrm{c}}}$

With the described apparatus and a value of $\varepsilon_{\mathrm{g}}=0.27$ at $\mathrm{D}_{\mathrm{s}}=10^{-3} \mathrm{~cm}^{2} . \mathrm{sec}^{-1}$ the second term of the series is less than $1 \%$ of the first term within 60 seconds. Therefore, only the first term of Eq. 10 was used. The solution becomes

$\mathrm{D}_{\mathrm{s}}=\frac{\varepsilon_{\mathrm{g}}}{\alpha_{\mathrm{t}}^{2}} 2.303 \log \frac{\mathrm{C}_{\mathrm{co}}}{\mathrm{C}_{\mathrm{ct}}}$

If diffusion coefficient calculated from Eq. $7\left(D_{\mathrm{s} 1}\right)$ is compared with that from Eq. $11\left(D_{s 2}\right)$, it appears that neglecting of the storage term of oxygen in the sample causes too low a calculated value $\left(D_{s 1}\right)$ of $D_{s}$. An approximation of $D_{s}$ for values $\frac{\varepsilon_{\mathrm{g}} \mathrm{h}_{\mathrm{s}}}{\mathrm{h}_{\mathrm{c}}} \leqslant 0.5$, below which value all the experiments were carried out, is:

$\mathrm{D}_{\mathrm{s}}=\mathrm{D}_{\mathrm{s} 2}=\left(1+0.342 \frac{\varepsilon_{\mathrm{g}} \mathrm{h}_{\mathrm{s}}}{\mathrm{h}_{\mathrm{c}}}\right) \mathrm{D}_{\mathrm{s} 1}$

A convenient way for the calculation of $D_{s}$ from oxygen concentration registrations is therefore the application of Eq. 7 and a correction for storage with Eq. 12. The maximum correction necessary in our experiments was $7 \%$ at an $\varepsilon_{\mathrm{g}}$ of 0.34 .

\section{Discussion of method}

\section{Ambient air}

The assumption that concentration gradients of oxygen outside the sample are of minor importance was tested on samples with a rather high $D_{s}$ of $10^{-2} \mathrm{~cm}^{2}$. sec-1. At such a high $D_{s}$ one may expect the greatest influence of diffusion resistances in the air outside the sample. Measurements were carried out with and without stirring the air below the sample and in the cap by small fans. Stirring appeared to have no measurable influence on the diffusion coefficients determined.

The oxygen diffusion coefficient in air was also determined in our apparatus. Samples of air-tight material were used with holes parallel to the walls of the sample ring. At $20^{\circ} \mathrm{C}$ and an air pressure of 1013 millibar the coefficient measured was $0.203 \mathrm{~cm}^{2}$. $\mathrm{sec}^{-1}$, with values given in literature of $0.200-0.216 \mathrm{~cm}^{2} \cdot \mathrm{sec}^{-1}$ at $20^{\circ} \mathrm{C}$ and $1013 \mathrm{mil}-$ libar (Smithonian Physical Tables, 1956; Willey and Tanner, 1964). 


\section{Oxygen consumption}

The oxygen consumption of the soil sample causes a supplemental decrease of oxygen concentration in the cap, resulting in a too high calculated value of $D_{s}$. At high microbiological respiration activities of the sample, the oxygen consumption will rise to about $2.10^{-6} \mathrm{~g} \mathrm{O}_{2} . \mathrm{cm}^{-3}$. hour-1 causing a decrease of about 0.1 vol. $\% \mathrm{O}_{2}$. hour ${ }^{-1}$ in the cap. This means that real values of $\mathrm{D}_{\mathrm{s}} / \mathrm{D}_{\mathrm{a}}$ of $0.05,0.01$ and zero are calculated to be, respectively, $0.05022,0.0101$ and 0.00009 (measurement lasting $5000 \mathrm{sec}$ ). Soil samples with an extremely low $D_{s}$ value show a relative high error. Usually, however, oxygen consumption of such soils, which are often almost saturated, is very low (Kzrysch, 1963). In our sample series the oxygen consumption was in the order of $0.5 \times 10^{-6} \mathrm{~g} \mathrm{O}_{2} . \mathrm{cm}^{-3}$. hour-1, causing an error of $\mathrm{D}_{\mathrm{s}} / \mathrm{D}_{2}$ of 0.1 to $1 \%$ at $\mathrm{D}_{\mathrm{s}} / \mathrm{D}_{\mathrm{a}}$ values of 0.05 and 0.002 , respectively.

\section{Oxygen concentration measurement}

During a run of $5000 \mathrm{sec}$, the error of the oxygen concentration measurement is about \pm 0.5 vol. $\% \mathrm{O}_{2}$. This means an error in $\mathrm{D}_{\mathrm{s}}$ of $\pm 5.10^{-5} \mathrm{~cm}^{2} \cdot \mathrm{sec}^{-1}$. For the determination of extreme low $D_{s}$ values, a longer test run is necessary. The accuracy of the oxygen measurement can be held within \pm 1 vol. $\% \mathrm{O}_{2}$ for 48 hours, which means an error in $D_{s}$ of $\pm 0.4 \times 10^{-5} \mathrm{~cm}^{2}$. sec-1. For saturated samples, therefore, the applied method is unsuitable since $D_{s}$ is in the order of $0.2 \times 10^{-6} \mathrm{~cm}^{2} . \mathrm{sec}^{-1}$. It is possible, however, to increase the sensitivity of the diffusion measurement by using thin samples and caps with a smaller volume.

\section{Temperature and pressure}

The effect of temperature and pressure on the diffusion coefficient can be represented by the equation (Smithonian Physical Tables)

$\mathrm{D}_{1}=\mathrm{D}_{2}\left(\frac{\mathrm{T}_{1}}{\mathrm{~T}_{2}}\right)^{1.75} \frac{\mathrm{p}_{1}}{\mathrm{p}_{2}}$

where $\mathrm{T}=$ absolute temperature $\left({ }^{\circ} \mathrm{K}\right)$ and $\mathrm{p}=$ pressure.

Temperature and pressure during the test runs were $20 \pm 3^{\circ} \mathrm{C}$ and $1013 \pm 25$ millibar. This will result in a deviation of $D_{s}$ of $2 \%$ due to temperature, and of $2.5 \%$ due to barometric pressure variation.

Apart from the direct effect on the diffusion, changes in temperature and barometric pressure during the measurement cause also a mass gas transport through the sample. The error in $D_{s}\left(\triangle D_{s}\right)$ with decreasing temperature or increasing barometric pressure, when gas storage in the sample is neglected, may be given as

$\Delta D_{s}=\frac{+h_{s} h_{c}}{t} 2.303 \log (1+x)$

$\mathbf{x}=$ being the relative change of absolute temperature or pressure.

Normally the changes of barometric pressure do not exceed 2 millibar during a measurement of $5000 \mathrm{sec}, 20$ millibar in 24 hours and 25 millibar in 48 hours. The maximum change of temperature was $1.5^{\circ} \mathrm{C}$ in $5000 \mathrm{sec}$ up to $3^{\circ} \mathrm{C}$ in 48 hours.

When, for example, $x$ is 0.005 (a decrease of temperature of $1.5^{\circ} \mathrm{C}$ or an increase of 
pressure of 5 millibar) during a measurement of $5000 \mathrm{sec}$, the error of $D_{8}$ is $3.6 \times$ $10^{-5} \mathrm{~cm}^{2} . \mathrm{sec}^{-1}$.

Increasing temperature or decreasing barometric pressure will have an opposite but smaller effect.

\section{Sample height}

The determination of sample height $\left(h_{s}\right)$ influences the accuracy of $D_{s}$ as well as that of $\varepsilon_{g}$. With a careful measurement the error of $h_{s}$ can be kept smaller than $\pm 0.5 \mathrm{~mm}$, resulting in an accuracy of $\mathrm{D}_{\mathrm{s}}$ of $\pm 1 \%$ and of $\varepsilon_{\mathrm{g}}$ of \pm 0.01 .

\section{Total error}

The total error of the $D_{s}$ values, as determined from the individual mentioned errors in the experiments, will be about $\pm 4, \pm 7$, \pm 15 and $\pm 100 \%$ for values of respectively $10^{-2}, 10^{-3}, 10^{-4}$ and $10^{-5} \mathrm{~cm}^{2}$. $\mathrm{sec}^{-1}$.

A series of test measurements on dry gypsum samples (with $D_{3}$ of about $2.10^{-3} \mathrm{~cm}^{2}$ $\sec ^{-1}$ ) showed a deviation of $\pm 5 \%$.

\section{Investigated soils}

The top layer of several marine soils of different soil structure was investigated, especially in regard to the degree of puddling at the moment of sampling.

Some additional remarks on the soils mentioned in Table 2 may be given here:

a. The soils in North Friesland are often puddled very badly during the winter period. Samples 1 and 2 were taken in a field with spring wheat. The topsoil had been cultivated after the winter period. Samples 3, 4 and 5 were taken in winter wheat,

Table 2 Data of investigated soil samples

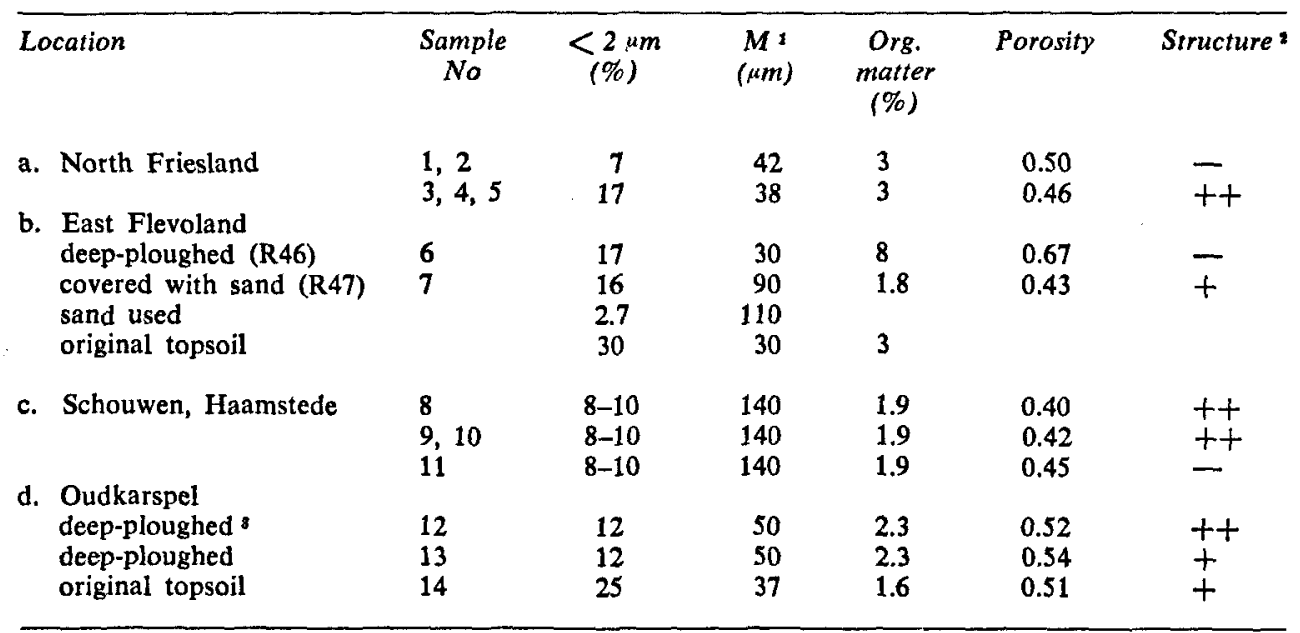

I $\mathrm{M}=$ medium size of particles $>2 \mu \mathrm{m}$.

$++=$ surface puddled $;=$ surface slightly puddled; $-=$ surface not puddled.

- Surface of sample artificially puddled. 
without tillage after winter, and showed severe symptoms of surface puddling.

b. In East Flevoland methods are investigated for improving the topsoil, in relation to possibilities of tillage. Sample 6 was taken from parcel R46 (deep-ploughed), with an excellent structure and a high content of organic matter in the topsoil. Sample 7 was obtained from parcel R47, which was covered with a sand layer of $8 \mathrm{~cm}$ and mixed to a depth of $18 \mathrm{~cm}$. Some signs of puddling existed, probably because of the low vertical permeability of the layer under the topsoil, which had been excessively compressed by machinery during land levelling. Due to the low permeability of this layer, the topsoil remained wet for a long period.

c. In the region behind the dunes near Haamstede, dune sand and clay soils have been mixed, showing a very dense structure (Kuipers, 1960). Samples 8, 9 and 10 were taken from plots with a dense and puddled topsoil with signs of anaerobic processes and bad crop growth. Sample 11 was obtained from a plot with a better structure and a good crop growth.

d. In deep-ploughed fields near Oudkarspel heavy loamy topsoil was exchanged with a light loamy subsoil. The lighter soil had a better structure whereas the original heavy soil did show a lower air content and a lower water permeability in winter and spring.

\section{Results and discussion}

The results of the diffusion measurements as given on logarithmic scale in Fig. 3 clearly demonstrate the influence of soil structure on the relationship between air porosity and the diffusion coefficient. The diffusion coefficient in the samples of puddled soils are, with the exception of Sample 6 from East Flevoland, considerably lower than the diffusion coefficient in non-puddled soils at equal air porosity values. For the nonpuddled topsoils the relation between $\varepsilon_{\mathrm{g}}$ and $\mathrm{D}_{\mathrm{s}}$ apparently can be described by the equation $\mathrm{D}_{\mathrm{s}} / \mathrm{D}_{\mathrm{a}}=0.85 \varepsilon_{\mathrm{g}}{ }^{2.0}$ and for the puddled topsoils by $\mathrm{D}_{\mathrm{s}} / \mathrm{D}_{\mathrm{a}}=2.0 . \varepsilon_{\mathrm{g}}{ }^{3.0}$. At an $\varepsilon_{\mathrm{g}}$ of $0.07, \mathrm{D}_{\mathrm{s}}$ in puddled soils is about one tenth of $\mathrm{D}_{\mathrm{s}}$ in non-puddled soils. At an $\varepsilon_{\mathrm{g}}$ of $0.14, \mathrm{D}_{\mathrm{s}}$ in puddled soils is one fourth of $\mathrm{D}_{\mathrm{s}}$ of non-puddled soils only. At $\varepsilon_{\mathrm{g}}>0.20$, however, differences become negligible. These results are in agreement with those of Domby and Kohnke (1956) on soil samples with a soil crust.

At low air porosities all measured values of $D_{s}$ are lower than the determinations published elsewhere (see the values in Table 1, taken from Taylor, 1949; Currie, 1961; Blake and Page, 1948; Gradwell, 1961). It is possible that the structure of the topsoil in our samples differs from that used by these authors. At values of $\varepsilon_{g}$ above 0.20 , the values of $D_{s}$ of the non-puddled soils fit the relationship given by Gradwell for dense-packed Kaolien aggregates (see Table 1).

The oxygen concentration in the soil atmosphere, necessary for good crop growth, depends on the respiration activity of the roots, the diameter of the roots and the thickness of the water film surrounding them (Grable, 1968; Lemon, 1962).

The percentage ranges from $<2$ vol. $\%$ in dry soils and thin roots up to $>20 \mathrm{vol} . \%$ under very wet conditions. Under wet conditions where a puddled surface inhibits the gas transport the drop of oxygen concentration in the water film will be considerable and the necessary oxygen concentration in the soil atmosphere therefore should be high, probably as high as the values of about 10 vol. \% given by Cannon (1925), Harris and van Bavel (1957), Geisler (1969). 


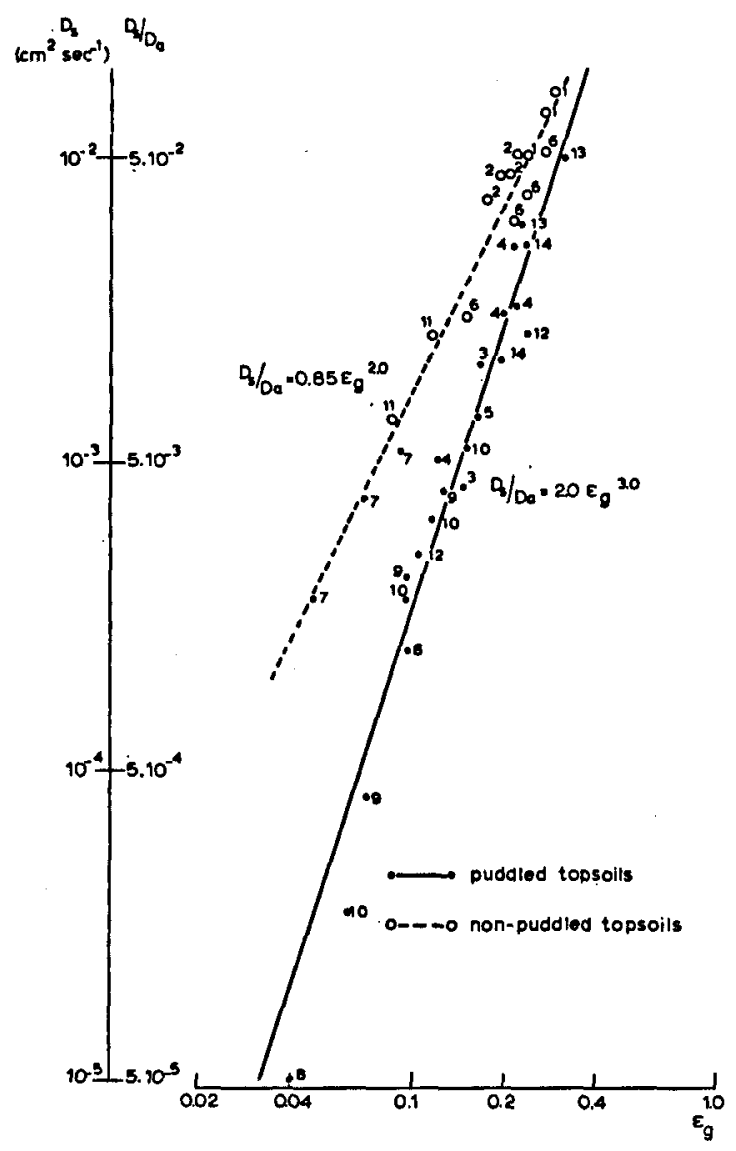

Fig. 3 Relationship of diffusion and air porosity for samples of non-puddled and puddled topsoils. For information on the samples (designated with numbers), see Table 2

Calculations of the gas transport in the soil profile have been made with decreasing $\mathrm{D}_{\mathrm{s}}$ and decreasing respiration activity at increasing depth (Wesseling, 1957; van Duin, 1956). Data on respiration activity in winter and early spring, however, are scanty, whereas for tulips, for example, this period seems to be of special importance. A simple model illustrates this problem on a soil with a surface layer of $5 \mathrm{~cm}$ thick without respiration activity, overlying a homogeneous active layer from 5 to $30 \mathrm{~cm}$ deep (Fig. 4).
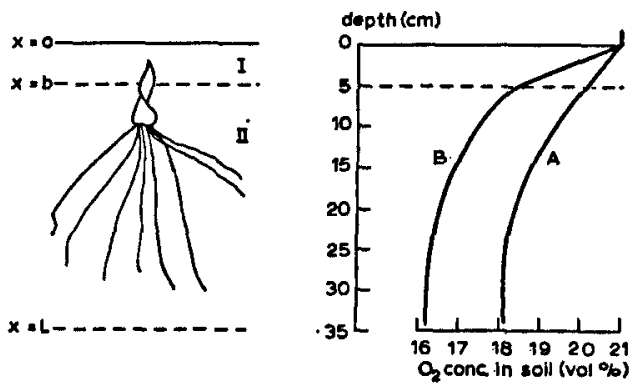

Fig. 4 Computed oxygen concentration in soil atmosphere of soils with a non-puddled (Curve A) and puddled topsoil (Curve B). $\varepsilon_{\mathrm{g}}$ of Layers 1 and $2=0.10 ; a$ of Layer $1=0 ; \alpha$ of Layer $2=0.132 \times 10-9 \mathrm{~g} \mathrm{O}$. $\mathrm{cm}^{-3}$. sec-1; $L=35 \mathrm{~cm}$ and $b=5 \mathrm{~cm}$ 
The concentration gradient of oxygen in the inactive Layer 1 is given by the equation

$\mathrm{dc}=-\frac{\alpha}{\mathrm{D}_{\mathrm{s}}} \mathrm{L}_{1} \mathrm{dx}$

and for the active Layer 2 :

$\mathrm{dc}=-\frac{a}{\mathrm{D}_{\mathrm{s}}} \mathrm{d}\left(\mathrm{L}_{1} \mathrm{x}_{1}-\frac{1}{2} \mathrm{x}_{1}^{2}\right)($ van Bavel, 1951)

$\alpha=$ oxygen consumption $\left(\mathrm{g} \mathrm{O}_{2} \cdot \mathrm{cm}^{-3} \cdot \mathrm{sec}^{-1}\right)$

$\mathrm{L}_{1}=\mathrm{L}-\mathrm{b}$

$\mathrm{x}_{1}=\mathrm{x}-\mathrm{b}$

$\mathrm{D}_{\mathrm{s}}=$ diffusion coefficient in the respective layer.

The value of $\alpha$ in Layer 2 is taken to be $0.132 \times 10^{-9} \mathrm{~g} . \mathrm{cm}^{-3} . \mathrm{sec}^{-1}$. With an $\varepsilon_{\mathrm{g}}$ in both layers of $0.10, \mathrm{D}_{\mathrm{s}}$ of non-puddled soil is in the order of $1.5 \times 10^{-3} \mathrm{~cm}^{2} . \mathrm{sec}^{-1}$ (Fig. 3). The drop in concentration calculated for these conditions in Layer 1 will be $0.8 \mathrm{vol} . \%$ $\mathrm{O}_{2}$ (Eq. 14) and in Layer 22.1 vol. $\% \mathrm{O}_{2}$ (Eq. 15), so that the total drop in concentration over $30 \mathrm{~cm}$ is $2.9 \mathrm{vol} . \%$. With a puddled surface layer $D_{s}$ of Layer 1 will be $0.45 \times 10^{-3} \mathrm{~cm}^{2} \cdot \mathrm{sec}^{-1}$ (Fig. 3). The drop in concentration in Layer 1 will be 2.8 vol. $\%$ causing a total decrease of 4.9 vol. $\% \mathrm{O}_{2}$.

At decreasing values of $\varepsilon_{\mathrm{g}}, \mathrm{D}_{\mathrm{s}}$ decreases quickly, especially in puddled soils. When $\varepsilon_{\mathrm{g}}$ is 0.07 , for instance, $\mathrm{D}_{\mathrm{s}}$ of a puddled and a non-puddled soil is $0.08 \times 10^{-3}$ and $0.75 \times$ $10^{-3} \mathrm{~cm}^{2} . \mathrm{sec}^{-1}$, respectively. Assuming an unaltered $\alpha$ of Layer 2, the resulting total decrease in concentration will be 5.8 and 19.9 vol. $\% \mathrm{O}_{2}$ with a non-puddled and a puddled surface layer, respectively. These figures show that under wet conditions the structure of the surface layer may become an extremely important factor for the aeration of a soil.

\section{References}

Bavel, C. H. M. van, 1951. A soil aeration theory based on diffusion, Soil Sci. 72: 33-46.

Bavel, C. H. M. van, 1952. Gaseous diffusion and porosity of porous media. Soil Sci. 73: 91-104.

Bergman, H. F., 1959. Oxygen deficiency as a cause of disease in plants. Bot. Rev. $25: 418-485$.

Blake, G. R. \& Page, J. B., 1948. Direct measurement of gaseous diffusion in soils. Proc, Soil Sci. Soc. Am. $13: 37-42$.

Boekel, P., 1963. Soil structure and plant growth. Neth. J. agric. Sci. 11: 120-127.

Boekel, P. \& Pelgrum, A., 1966. Bodemfysisch onderzoek op enkele percelen tulpen in Noord-Holland. Groningen, I.B. Rapport No 4, pp. 8.

Buckingham, E., 1904. Contribution to our knowledge of the aeration of soils. Bull. Div. Soils U.S. Dep. Agric. 25, pp. 51.

Call, F., 1957. Soil fumugation. V. Diffusion of ethylene dibromide through soils. J. Sci. Food Agric. 8: $143-150$.

Cannon, W. A., 1925. Physical features of roots with especial reference to the relation of roots to aeration of the soil. Publs Carnegie Instn 368, pp. 168.

Currie, J. A., 1960. Gaseous diffusion in porous media. I. A non-steady state method, Br. J. appl. Phys. 11: 314-324.

Currie, J. A., 1961. Gaseous diffusion in porous media. III. Wet granular material. Br. J. appl. Phys. 12: $275-281$.

Duin, R. H. A. van, 1956. On the influence of tillage on the conduction of heat, diffusion of air and infiltration of water in soil (Dutch), Versl. landbouwk. Onderz. 62.7. 
Domby, C. W. \& Kohnke, H., 1956. The influence of soil crust on gaseous diffusion. Proc. Soil Sci. Soc. Am. 20: 1-5.

Geisler, G., 1969. Die Wirkung der Sauerstoff und Kohlensäurekonzentration in der Bodenluft auf Sprosz- und Wurzelwachstum von Wintergerste, Mais und Erbsen. Bayer. landw. Jb. 46: 259-278.

Grable, A. R. \& Siemer, E. G., 1968. Effects of bulk density, aggregate size and soil water suction on oxygen diffusion, redox potentials and elongation of corn roots. Proc. Soil Sci. Soc. Am. 32: $180-186$.

Gradwell, M. W., 1961. A laboratory study of the diffusion of oxygen through pasture topsoils. N.Z. Jl Sci. 4: 250-270.

Gradwell, M. W., 1965. Soil physical conditions of winter and the growth of rye grass plants. I. The effects of compaction and puddling. N.Z. Jl agric. Res. 8: 238-269.

Harris, D. G. \& Bavel, C. H. M. van, 1957. Growth, yield and water absorption of tobacco plants as affected by the composition of the root atmosphere. Agron. J. 49:11-14; 176-184.

Kuipers, S. F., 1960. A contribution to the knowledge of soils of Schouwen-Duiveland and Tholen accorling to the conditions prior to 1953 (Dutch). Versl. landbouwk. Onderz. 65.7.

Lemon, E. R., 1962. Soil aeration and plant-root relations. Agron. J. 54: 167-170.

Penman, H. L., 1940. Gas and vapour movements in the soil (I and II). J. agric. Sci. Camb. 30 : $447-462 ; 570-581$.

Romell, L. G., 1922. Der Bodenventilation als ökologischer Faktor. Meddn St. Skogsförs Anst. 19 : 125-359.

Smithonian Physical Tables, 9th ed. New York, Smithonian Institution, 1956.

Taylor, S. A., 1949. Oxygen diffusion as a measure of soil aeration. Proc. Soil Sci. Soc. Am. 14: 55-60.

Wesseling, J., 1957. Some aspects of the water government in agricultural soils (Dutch). Versl. landbouwk. Onderz. 63.5.

Willey, C. R. \& Tanner, C. B., 1964. A steady-state method for laboratory measurement of the oxygen diffusivity of porous materials. Proc. Soil Sci. Soc. Am. 28: 733-737. 